\title{
The increased ventilatory response to exercise in chronic heart failure: relation to pulmonary pathology
}

\author{
Andrew L Clark, Maurizio Volterrani, Jonathan W Swan, Andrew J S Coats
}

\begin{abstract}
Objective-To assess the exercise limitation of patients with chronic heart failure (CHF) and its relation to possible pulmonary and ventilatory abnormalities.

Setting-A tertiary referral centre for cardiology.

Methods-The metabolic gas exchange responses to maximum incremental treadmill exercise were assessed in 55 patients with CHF (mean (SD) age 57.9 (13.0) years; 5 female, 50 male) and 24 controls (age 53.0 (11.1) years; 4 female, 20 male). Ventilatory response was calculated as the slope of the relation between ventilation and carbon dioxide production ( $\dot{\mathbf{V}} / \mathbf{V} \mathrm{CO}_{2}$ slope).

Results-Oxygen consumption $\left(\mathrm{V}_{2}\right)$ was the same at each stage in each group. Ventilation ( $\dot{V} E$ ) was higher in patients at each stage. Patients had a lower peak Vंo and a steeper $\dot{V} \mathrm{E} / \dot{V} \mathrm{CO}_{2}$ slope than controls. Dead space ventilation as a fraction of tidal volume (VD/VT) was higher in patients at peak exercise, but dead space per breath was greater in controls at peak $\begin{array}{llllll}\text { exercise } & (0.74 & (0.29) & v & 0.57 & (0.17)\end{array}$ litres/breath; $P=0 \cdot 002$ ). End tidal $\mathrm{CO}_{2}$ was lower in patients at all stages, and correlated with peak $\dot{\mathbf{V}} \mathrm{O}_{2}(r=0.58, P<$ $0.001)$. Alveolar oxygen tension was higher in patients at each stage than in controls.
\end{abstract}

Conclusions-Patients with CHF have an increased ventilatory response at all stages of exercise. Although this is accompanied by an increase in $\mathrm{VD} / \mathrm{VT}$, there is hyperventilation relative to blood gases. It is more likely that the excessive ventilation is not due to a primary pulmonary pathology, but rather, the increase in dead space is likely to be a response to increased ventilation.

Department of

Cardiac Medicine,

National Heart and

Lung Institute,

London, United

Kingdom

A L Clark

M Volterrani

$J$ W Swan

A J S Coats

Correspondence to:

Dr A L Clark, Department

of Cardiology, Western

Infirmary, Dumbarton Road,

Glasgow G11 6NT.

Accepted for publication

16 October 1996
(Heart 1997;77:138-146)

Keywords: metabolic gas exchange; dead space ventilation; chronic heart failure; exercise

The cardinal feature of the syndrome of chronic heart failure is exercise limitation. The symptoms causing limitation are most frequently shortness of breath and muscle fatigue. Either symptom can occur in the same patient depending upon the type of exercise undertaken. ${ }^{12}$ The syndrome is commonly assessed clinically using incremental exercise protocols to determine ventilation and metabolic gas exchange. Peak exercise capacity is measured as peak oxygen consumption $\left(\mathrm{V}_{2}\right)$, although the reduction in peak $\mathrm{VO}_{2}$ characteristic of chronic heart failure correlates only poorly with indices of haemodynamic function. ${ }^{134}$ Many investigators have shown that there is an increase in ventilation, ${ }^{5-7}$ and this increase in ventilation ( $\dot{V} E$ ) expressed as an increase relative to the rate of carbon dioxide production $\left(\dot{\mathrm{V}} \mathrm{CO}_{2}\right)$, as $\dot{\mathrm{V}} \mathrm{E} / \dot{\mathrm{V}} \mathrm{CO}_{2}$ slope, correlates closely with reduction in peak $\mathrm{VO}_{2} .{ }^{89}$

To account for the increased ventilatory response, several investigators have proposed that dead space ventilation is increased, ${ }^{7}{ }^{1011}$ although how this abnormality is sensed is difficult to imagine, given the stability of arterial blood gas tensions during exercise in heart failure. $^{1213}$ We have explored the relations between ventilation, blood gas tensions, dead space, and metabolic gas exchange in a large group of patients with chronic heart failure and age matched controls in an attempt to determine the cause of the ventilatory abnormalities.

\section{Methods}

We examined the responses of 55 patients (average age 57.9 (SD 13.0) years; five female, 50 male) with documented treated, stable chronic heart failure. The diagnosis was confirmed by the presence of at least the following: (1) evidence of impaired left ventricular function from radionuclide scanning, cross sectional echocardiography, or cardiac catheterisation; and (2) a cardiothoracic ratio of greater than 0.5 , a left ventricular ejection fraction of less than 0.45 , abnormal left ventricular chamber dimensions, or raised end diastolic pressure. Exercise tests were undertaken as part of their routine assessment. No patient had any intercurrent illness. Patients with a past history of lung disease, or who were current smokers, were excluded from analysis. All patients had been clinically stable and on stable medication for at least three months before exercise testing, and all patients were limited by either fatigue or shortness of breath on exercise. No patient had peripheral or pulmonary oedema. No patient was stopped by angina or claudication. Details of diagnosis and medication are given in table 1 . The average forced expiratory volume in one second $\left(\mathrm{FEV}_{1}\right)$ was $96.7 \%$ of the expected and the forced vital capacity (FVC) was $93.5 \%$ of expected. No patient with results less than $75 \%$ of expected was included in this study. 
Table 1 Patient characteristics

\begin{tabular}{ll}
\hline & $\begin{array}{l}\text { Patients } \\
(n=55)\end{array}$ \\
\hline Age (years) (SD) & $57 \cdot 9(13 \cdot 0)$ \\
LVEF (\%) (SD) & $28 \cdot 8(14)$ \\
Weight (kg) (SD) & $79 \cdot 5(13 \cdot 7)$ \\
NYHA: & \\
I & 13 \\
II & 13 \\
III & 19 \\
IV & 10 \\
Diagnosis: & \\
DCM & 24 \\
IHD & 31 \\
Drugs: & \\
Diuretic & 46 \\
ACEI & 35 \\
Digoxin & 18 \\
Other VD & 15 \\
\hline
\end{tabular}

LVEF, left ventricular ejection fraction from radionuclid scanning ( $\mathrm{n}=37$ ); NYHA, New York Heart Association symptom score classification; DCM, dilated cardiomyopathy; IHD, ischaemic heart disease; Diuretic = frusemide, average dose 85.1 (SD 41.7) mg/d; ACEI, angiotensin converting enzyme inhibitor; Other VD, other vasodilator.

18 patients were in atrial fibrillation. The numbers in the right 18 patients wh the right hand column are the numbers of patients in each group. The ( $\mathrm{P}=\mathrm{NS})$, and average weight was $80.7(13 \cdot 4) \mathrm{kg}(\mathrm{P}=\mathrm{NS})$.

Twenty four control subjects were recruited from patients attending for routine medical examinations (four female, 20 male). No subject was a current smoker, or gave any history of past cardiorespiratory disease. None was taking intercurrent medication. Average age was $53.0(11 \cdot 1)$ years. Fully informed signed consent was obtained from each subject, and all procedures had been approved by the local ethics committee.

The exercise protocol used was a standard Bruce treadmill protocol modified by the addition of a "stage 0 " at the onset of exercisethat is three minutes of exercise at 1 mile per hour with a $5 \%$ gradient. Subjects were encouraged to exercise to exhaustion. Subjects breathed through a one way valve connected to a mass spectrometer (Amis 2000; Odense, Denmark) allowing expired air to be collected; metabolic gas exchange and ventilation were determined on line every 10 seconds by a standard inert gas dilution technique. ${ }^{214}$ A second mass spectrometer inlet allowed end tidal carbon dioxide and oxygen tensions to be measured. Respiratory rate was counted from the capnograph.

Data were taken after a minimum of three minutes resting while the subject was attached to the apparatus. Resting readings were only taken when the reading for ventilation was stable over at least 30 seconds. At the end of each stage, and at peak exercise, the data for the last three readings were averaged to give a single reading. Fractional dead space was calculated from the alveolar ventilation equation:

$$
\dot{\mathrm{V}} \mathrm{E}=\dot{\mathrm{V}} \mathrm{CO}_{2} \times 863 / \mathrm{PaCO}_{2} \times(1-\mathrm{VD} / \mathrm{VT})
$$

where $\dot{V}_{E}$ is minute ventilation, $V D / V T$ describes dead space ventilation as a proportion of tidal ventilation, $\mathrm{PaCO}_{2}$ is the arterial partial pressure of carbon dioxide, and 863 is a constant to standardise gas measurements to body temperature, pressure and saturation. End tidal carbon dioxide tension was assumed to equate with arterial carbon dioxide tension, ${ }^{10}$ and was calculated as:
$\mathrm{Pa}(\mathrm{gas})=\left(\mathrm{F}_{\mathrm{ET}}(\mathrm{gas}) / 100 \times(\mathrm{BP}-47) / 7 \cdot 5\right)$

where $\mathrm{Pa}$ (gas) is the arterial partial pressure of a gas, $\mathrm{F}_{\mathrm{ET}}$ (gas) is the fractional concentration of end tidal gas, BP is barometric pressure $(\mathrm{mm} \mathrm{Hg}), 47$ is the partial pressure of water vapour, and 7.5 converts from $\mathrm{mm} \mathrm{Hg}$ to $\mathrm{kPa}$. Alveolar oxygen tension was calculated in a similar manner.

Absolute dead space ventilation (ADV) was calculated from:

$$
\mathrm{ADV}=\dot{\mathrm{V}} \mathrm{E} \times(\mathrm{VD} / \mathrm{VT})
$$

and dead space per breath (DS/Br) was calculated from:

$$
\mathrm{DS} / \mathrm{Br}=\mathrm{ADV} / \text { respiratory rate }
$$

With the exception of the peak exercise measurements, these derived variables were only calculated at the end of each three minute stage to allow steady state gas exchange to be present. ${ }^{15}$

Unpaired $t$ tests were used to compare patient and control groups. The heart failure group was divided into two groups on the basis of severity of heart failure (see below). As there was drop out of the more severely affected heart failure patients between stages 1 and 2, statistical analysis of the effects of diagnostic group and exercise performance was restricted to resting, stage 1 , and peak exercise. To establish trends across the controls and patient groups during exercise, a repeated measures analysis of variance was used, with severity of heart failure as a factor and stage of exercise as a repeated measures factor, corrected for multiple comparisons with Scheffe's procedure. Linear regression by the least squares method was used to determine correlations between variables. Results are quoted as means (SD), or where a paired $t$ test comparison is made as mean (SEM). Corrected $P$ values of less than 0.05 were taken to be significant.

\section{Results}

EXERCISE VARIABLES

Table 2 shows the overall results obtained during exercise. As expected, the peak $\dot{\mathrm{V}}_{2}$ was greater $(P<0.001)$ in the controls than in the patients with heart failure, and exercise time was greater $(\mathrm{P}<0.001)$. The $\dot{\mathrm{VE}} / \mathrm{VCO}_{2}$ slope was steeper in the patient group $(P<0.001)$, but the respiratory exchange ratio (RER) at peak exercise was similar in each group. RER was greater than 1 in all cases, indicating that at least near maximal exercise had been reached.

In the patient group there was an inverse relation between peak $\dot{\mathrm{VO}}_{2}$ and $\dot{\mathrm{VE}} / \mathrm{V}_{\mathrm{CO}_{2}}$, as previously reported, ${ }^{8}$ but this was not seen among the normal subjects. ${ }^{9}$ The relation was best described by a semi-log curve $\left(\dot{\mathrm{V}} / \dot{\mathrm{V}}_{\mathrm{CO}}\right.$ slope $=70.55-29.19 \times \log \dot{V}_{2} ; r=0.65$; $P<0.001$ ) (fig 1).

\section{METABOLIC GAS EXCHANGE}

There was no significant difference between the groups in $\dot{\mathrm{VO}}_{2}$ and $\dot{\mathrm{VCO}}_{2}$ at the end of each stage of exercise, as would be expected given the similar external work loads. Thus resting 
Table 2 Results from overall exercise data

\begin{tabular}{lccl}
\hline & $\begin{array}{c}\text { Patients } \\
(n=55)\end{array}$ & $\begin{array}{c}\text { Controls } \\
(n=24)\end{array}$ & $P$ \\
\hline Peak $\dot{\mathrm{VO}}_{2}(\mathrm{ml} / \mathrm{kg} / \mathrm{min})$ & $19 \cdot 6(7 \cdot 1)$ & $33.6(1 \cdot 8)$ & $<0.001$ \\
$\mathrm{VE} / \mathrm{V} \mathrm{CO}_{2}$ & $33.5(9 \cdot 2)$ & $25 \cdot 9(3 \cdot 37)$ & $<0.001$ \\
$\mathrm{Time}(\mathrm{s})$ & $505(227)$ & $864(166)$ & $<0.001$ \\
$\mathrm{RER}$ & $1 \cdot 16(0 \cdot 12)$ & $1.22(0 \cdot 10)$ & NS \\
\hline
\end{tabular}

Peak $\mathrm{VO}_{2}$, peak achieved oxygen consumption; $\mathrm{VE} / \mathrm{VCO}_{2}$, slope of the relation between ventilation and carbon dioxide production (both measured as $\mathrm{ml} / \mathrm{kg} / \mathrm{min}$, hence $\mathrm{VE} / \mathrm{V} \mathrm{CO}_{2}$ is dimensionless); Time, total exercise time in seconds; RER, respiratory exchange ratio $\left(\mathrm{VCO}_{2} / \mathrm{VO}_{2}\right)$ at peak exercise.

$\mathrm{P}$ values refer to unpaired $t$ tests between the two columns.

Table 3 Effects of severity of heart failure. Values are means (SD)

\begin{tabular}{lccl}
\hline & $\begin{array}{l}\text { Mild } \\
(n=28)\end{array}$ & $\begin{array}{l}\text { Severe } \\
(n=27)\end{array}$ & $P$ \\
\hline $\mathrm{LVEF}(\%)$ & $31 \cdot 0(13 \cdot 9)$ & $26 \cdot 4(13 \cdot 9)$ & $\mathrm{NS}$ \\
$\mathrm{Peak} \mathrm{VO} \mathrm{VO}_{2}(\mathrm{ml} / \mathrm{kg} / \mathrm{min})$ & $25 \cdot 1(5 \cdot 6)$ & $13 \cdot 9(2 \cdot 7)$ & $<0 \cdot 001$ \\
$\mathrm{VE} / \mathrm{V} \mathrm{CO}_{2}$ & $29 \cdot 3(7 \cdot 3)$ & $37 \cdot 8(9 \cdot 0)$ & $<0 \cdot 001$ \\
$\mathrm{RER}$ & $1 \cdot 14(0 \cdot 10)$ & $1 \cdot 18(0 \cdot 13)$ & $\mathrm{NS}$ \\
Time (s) & $672(166)$ & $332(134)$ & $<0 \cdot 001$ \\
\hline
\end{tabular}

Patients have been divided into two groups on the basis of their peak $\mathrm{VO}_{2}$. Those with a peak $\mathrm{VO}_{2}$

less than $17 \mathrm{ml} / \mathrm{kg} / \mathrm{min}$ were considered to have severe heart failure.
$\dot{\mathrm{V}} \mathrm{O}_{2}$, peak achieved oxygen consumption; $\mathrm{VE} / \mathrm{V}_{\mathrm{CO}_{2}}$, slope of the relation between ventilation and carbon dioxide production; Time, total exercise time in seconds; RER, the respiratory exchange ratio $\left(\mathrm{VCO}_{2} / \mathrm{VO}_{2}\right)$ at peak exercise.

$P$ values refer to unpaired $t$ tests between the two columns.

Table 4 Respiratory gases during exercise. Values are means (SD)

\begin{tabular}{|c|c|c|c|c|}
\hline & & Stage 1 & Peak & $P$ \\
\hline \multirow[t]{2}{*}{ Controls $(n=24)$} & $\mathrm{PaCO}_{2}$ & $6 \cdot 02(0 \cdot 10)$ & $5 \cdot 71(0 \cdot 12)$ & 0.004 \\
\hline & $\mathrm{P}_{\mathrm{A}} \mathrm{O}_{2}$ & $13.36(0.14)$ & $15 \cdot 04(0 \cdot 14)$ & $<0.001$ \\
\hline \multirow{2}{*}{ Mild HF $(n=28)$} & $\mathrm{PaCO}_{2}$ & $5.45(0.16)$ & $5.08(0.16)$ & $<0.001$ \\
\hline & $\mathrm{P}_{\mathrm{A}} \mathrm{O}_{2}$ & $14.26(0.18)$ & $15.39(0 \cdot 16)$ & $<0.001$ \\
\hline \multirow[t]{2}{*}{ Severe HF $(n=13)$} & $\mathrm{PaCO}_{2}$ & $4.77(0.23)$ & $4.45(0.19)$ & $<0.007$ \\
\hline & $\mathrm{P}_{\mathrm{A}} \mathrm{O}_{2}$ & $15 \cdot 38(0 \cdot 31)$ & $16 \cdot 07(0 \cdot 24)$ & $<0.002$ \\
\hline
\end{tabular}

Results are shown for the comparison between end of stage 1 and peak exercise. $\mathrm{PaCO}_{2}$ is calcu lated arterial carbon dioxide tension, and $\mathrm{P}_{\mathrm{A}} \mathrm{O}_{2}$ is alveolar oxygen tension. Values are in $\mathrm{kPa}$. $\mathrm{P}$ values refer to paired $t$ test comparisons between peak and stage 1 values; hence values in this table are means (SEM).

$\dot{\mathrm{V}} \mathrm{O}_{2}$ was $5 \cdot 10(1 \cdot 31) \mathrm{ml} / \mathrm{kg} / \mathrm{min}$ in the patients and $5 \cdot 15(1.53)$ in the controls; and 14.79 $(2 \cdot 89)$ at the end of stage 1 in the patients and $16.43(3.50)$ in controls. There was, however, dropout of subjects between stages, particularly marked in the heart failure group, as subjects reached their maximum tolerated exercise level-from 55 patients at rest, only 41 reached the end of stage 1 .

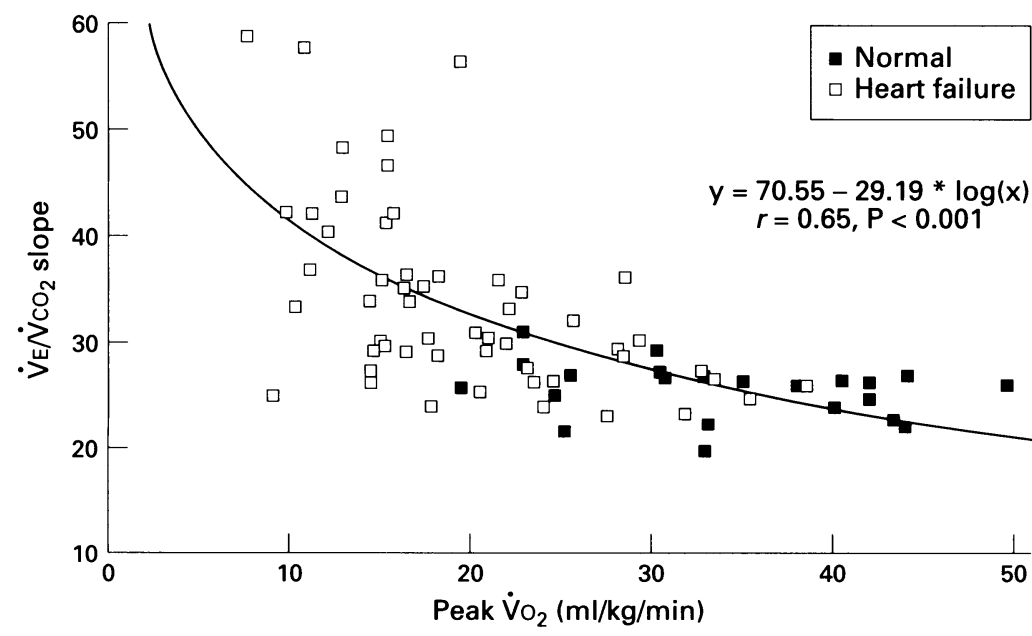

Figure 1 The relation between peak $\dot{V O}_{2}$ and $\dot{V} E / \dot{V C O}_{2}$ slope. The curve through the points is best described by a logarithmic relation.
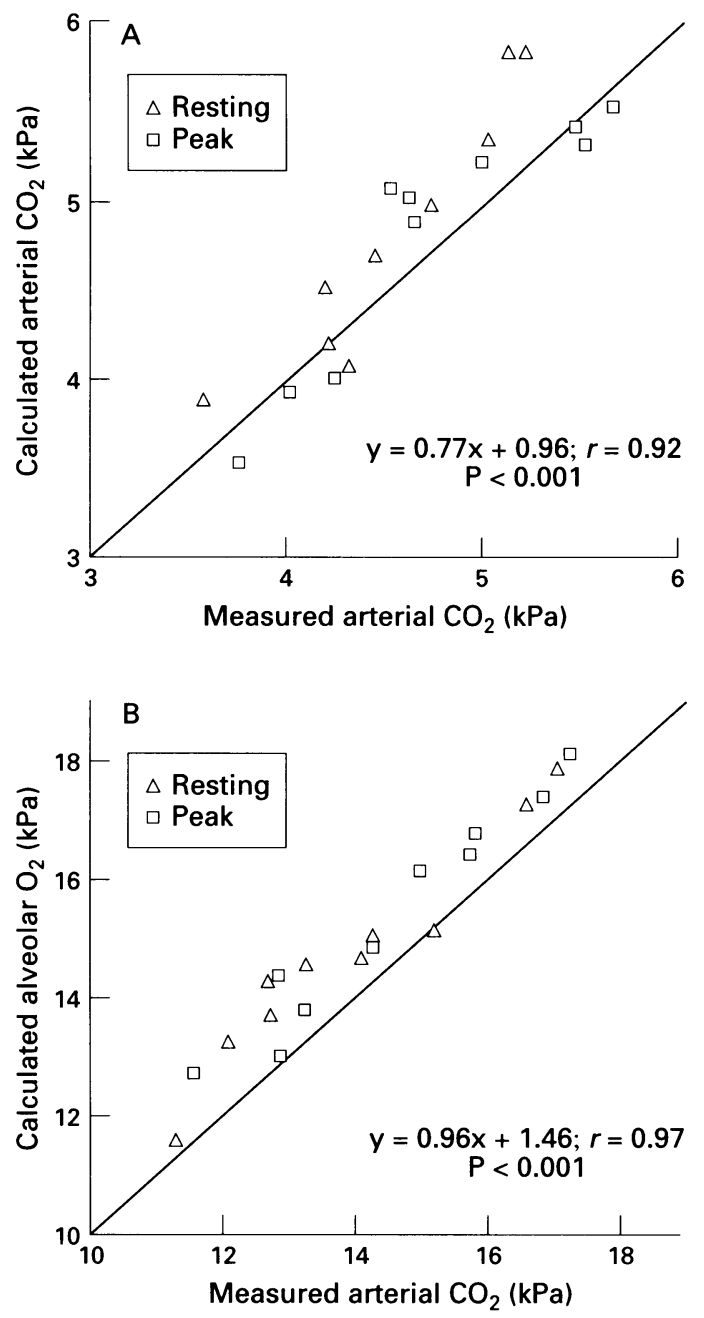

Figure 2 Plots of measured arterial blood gases and values for arterial carbon dioxide and alveolar oxygen partial pressures calculated from end tidal fractions. The lines are the lines of identity.

EFFECTS OF SEVERITY OF HEART FAILURE

In order to assess the effects of severity of heart failure, the patients were divided into two groups on the basis of their peak $\dot{\mathrm{V}}_{2}$ : group 1, mild heart failure and group 2, severe heart failure. A division at $17 \mathrm{ml} / \mathrm{kg} / \mathrm{min}$ was chosen to allow comparison of similar numbers of patients. The breakdown of patients is shown in table 3 . There were no significant differences between the two patient groups in indices of metabolic gas exchange at each stage. After stage 1, the numbers of patients in the severely affected group fell off so as not to allow further comparisons at matched workloads.

RESPIRATORY GASES

The end tidal $\mathrm{CO}_{2}$ for patients at each stage was: rest, 5.14 (0.73)\%; stage 1, $5.47(0.93)$; stage $2,5.66(0.73)$; stage $3,5.79(0.60)$; and peak exercise $4.98(1.06)$. For the control group, end tidal $\mathrm{CO}_{2}$ was: rest, $5.54(0.46) \%$; stage $1,6.27(0.53)$; stage $2,6.38(0.61)$; stage 3, 6.31 (0.66) and peak exercise, 5.94 (0.60). End tidal oxygen in patients was: rest, $15 \cdot 17$ (0.97)\%; stage $1,15.28$ (1.15); stage $2,15.45$ $(0.93)$; stage $3,15.54(0.36)$; and peak exercise, $16 \cdot 31(1 \cdot 17)$. For the control group, end tidal oxygen was: rest, $14 \cdot 44(0 \cdot 76) \%$; stage 1 , $13.91(0.67)$; stage $2,14.24(0.80)$; stage 3 , $14 \cdot 82(0 \cdot 84)$; and peak exercise, $15 \cdot 66(0 \cdot 71)$. 

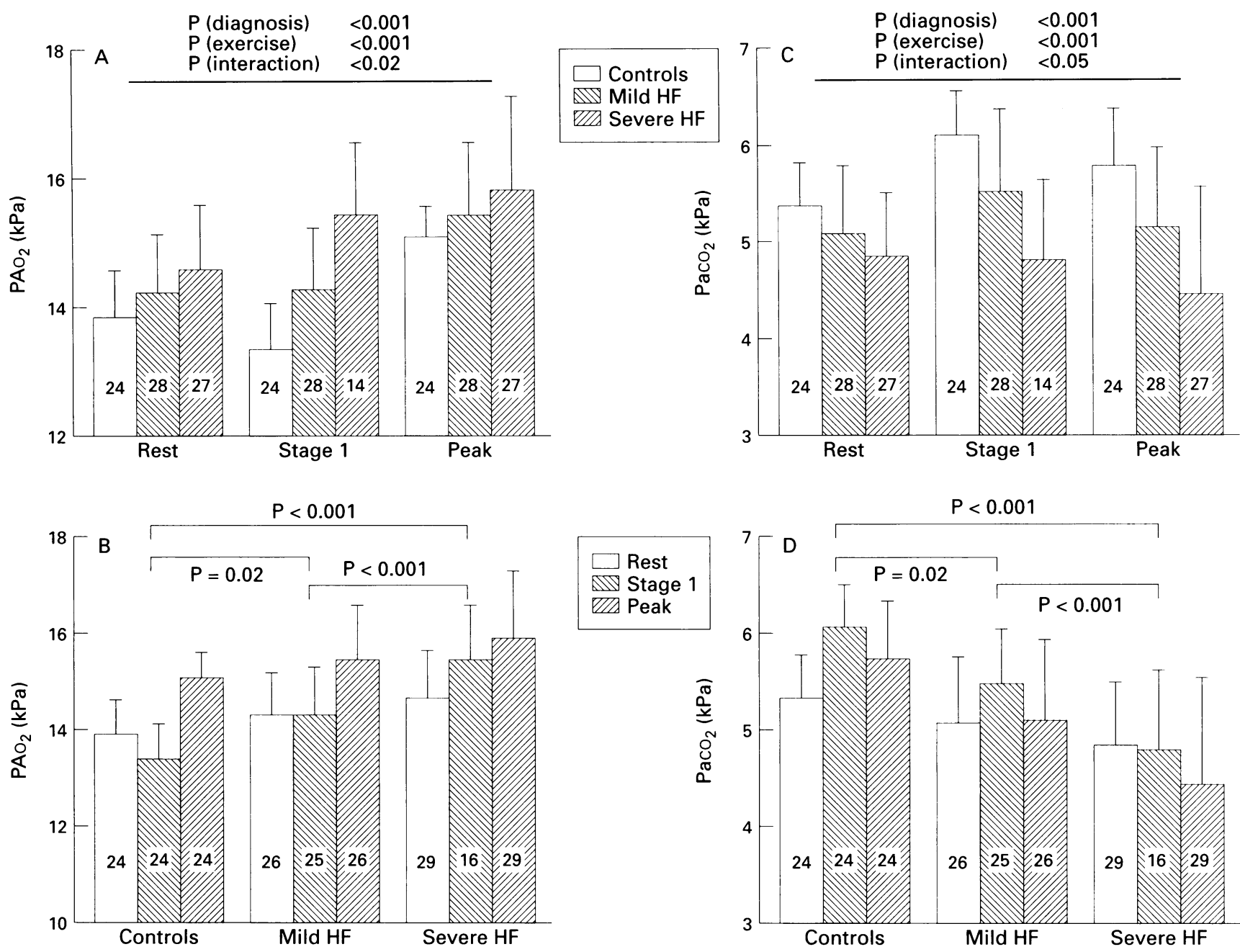

Figure 3 The behaviour of arterial carbon dioxide $\left(\mathrm{PaCO}_{2}\right)$ and alveolar oxygen $\left(\mathrm{PAO}_{2}\right)$ during exercise. In these and subsequent plots, we have used factorial analysis of variance to analyse the effects of diagnostic category, the effects of exercise, and the effect of diagnostic category on the exercise responses. The $P$ values are explained as follows: $P$ (diagnosis) is for the effect of diagnostic category (controls, mild heart failure (HF), and severe heart failure) on the variable; $P$ (exercise) is for the effect of exercise stage on the variable, $P$ (interaction) is for the interaction between the two variables, ie, how diagnostic category affects the behaviour of a variable during exercise. Panels (B) and (D) show the behaviour of gases grouped according to diagnostic category.

In order to assess the possible effects of heart failure on the calculations of arterial carbon dioxide and alveolar oxygen tensions from end tidal fractional concentrations, and thus to ensure that the data from end tidal fractional gas concentrations were valid, we measured arterial blood gas tensions in 10 patients at rest and at peak exercise. The measured arterial carbon dioxide tension was the same as calculated arterial carbon dioxide tension: 4.67 $(0.20) \mathrm{kPa} v 4.95(0.26)$ at rest; $4.75(0.20) v$ $4.79(0.22)$ at peak exercise. The mean (SD) of the differences between measured and calculated arterial $\mathrm{PaCO}_{2}$ was $0 \cdot 16(0 \cdot 30)$. The arterial oxygen tension was non-significantly lower than the calculated alveolar tension at rest $(13.89(0.60) v 14.81(0.58)$ : NS), achieving significance at peak exercise $(14.50(0.60) v$ 15.44 (0.60): $P=0.004$ ) (fig 2). The mean (SD) of the differences between arterial and alveolar (end tidal) $\mathrm{O}_{2}$ was $-0.93(0.47)$. Thus arterial carbon dioxide tension calculated from end tidal fraction is, as expected from the diffusion characteristics of carbon dioxide, an accurate reflection of arterial carbon dioxide. The alveolar oxygen tension calculated from end tidal oxygen fraction, however, signifi- cantly overestimates the arterial oxygen tension. This is consistent with an alveolararterial oxygen difference in the order of $1 \mathrm{kPa}$ (fig 2).

Figure $3 \mathrm{~A}-\mathrm{D}$ shows the behaviour of the calculated arterial carbon dioxide tension and alveolar oxygen tension $\left(\mathrm{PAO}_{2}\right)$ across the three groups: controls, mild heart failure, and severe heart failure. Note that at each comparison, the patient groups have a higher $\mathrm{PAO}_{2}$ and a lower $\mathrm{PaCO}_{2}$. The differences within each group from stage 1 to peak exercise are shown in table 4 ; the carbon dioxide tension falls and the oxygen tension rises in each group.

\section{VENTILATION}

There was no difference between the three groups in ventilation at rest: $12.5(3.5) 1 / \mathrm{min}$ in the controls, $14.7(4.0)$ in the mild heart failure group, and $14.6(3.9)$ in the severe heart failure group. At the end of stage 1 exercise, ventilation was greater in patients than in controls, and greater in the more severely affected patients: controls $32.4(10.5) \mathrm{l} / \mathrm{min}$; mild heart failure $(n=28) 35.9(9 \cdot 3)$; severe heart failure $(\mathrm{n}=14) 44 \cdot 1(13 \cdot 2): \mathrm{P}<0.001$ 

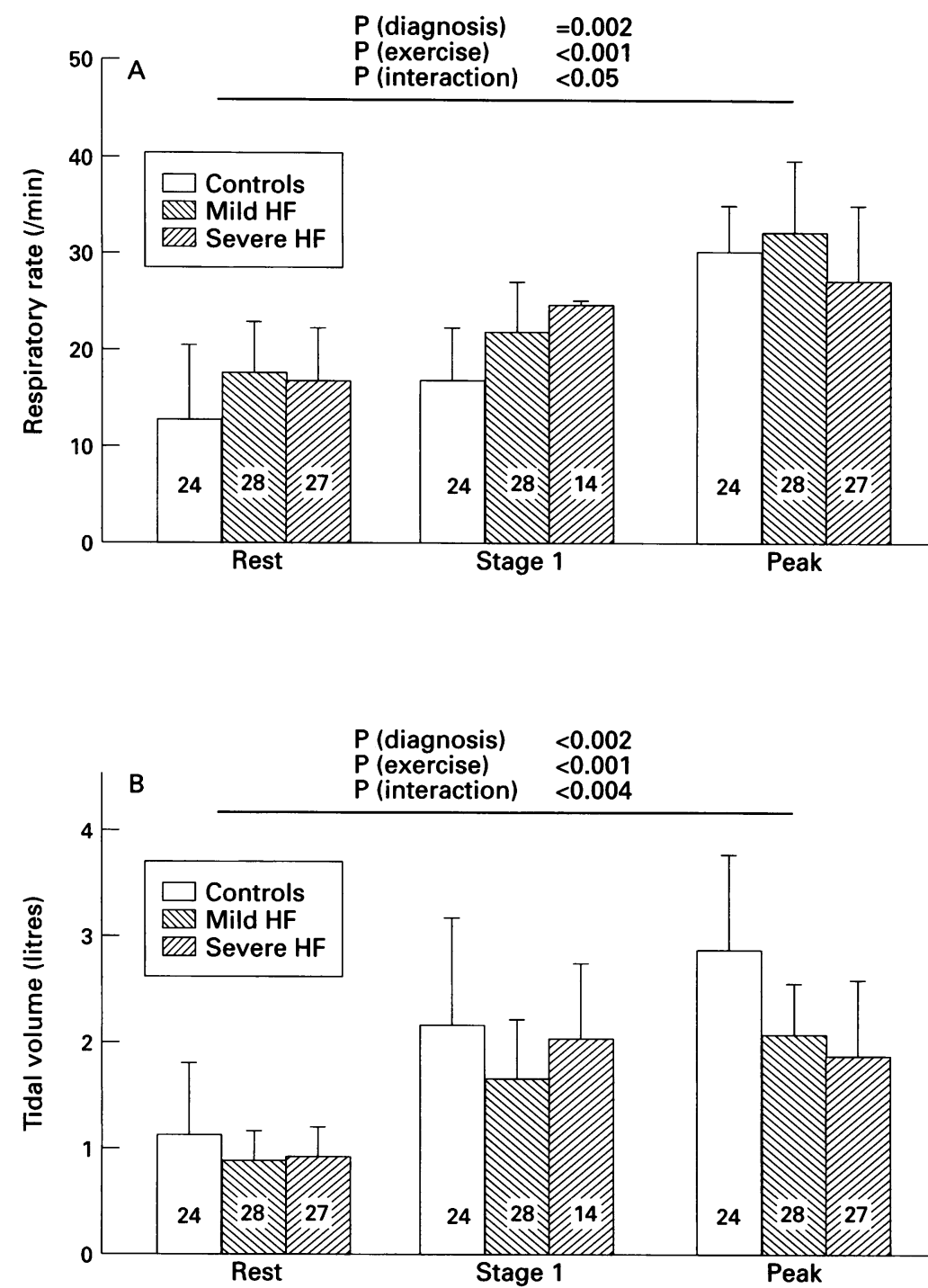

Figure 4 Respiratory rate and tidal volume during exercise. P values as for fig 3.

Table 5 Effects of severity of heart failure. Values are means (SD)

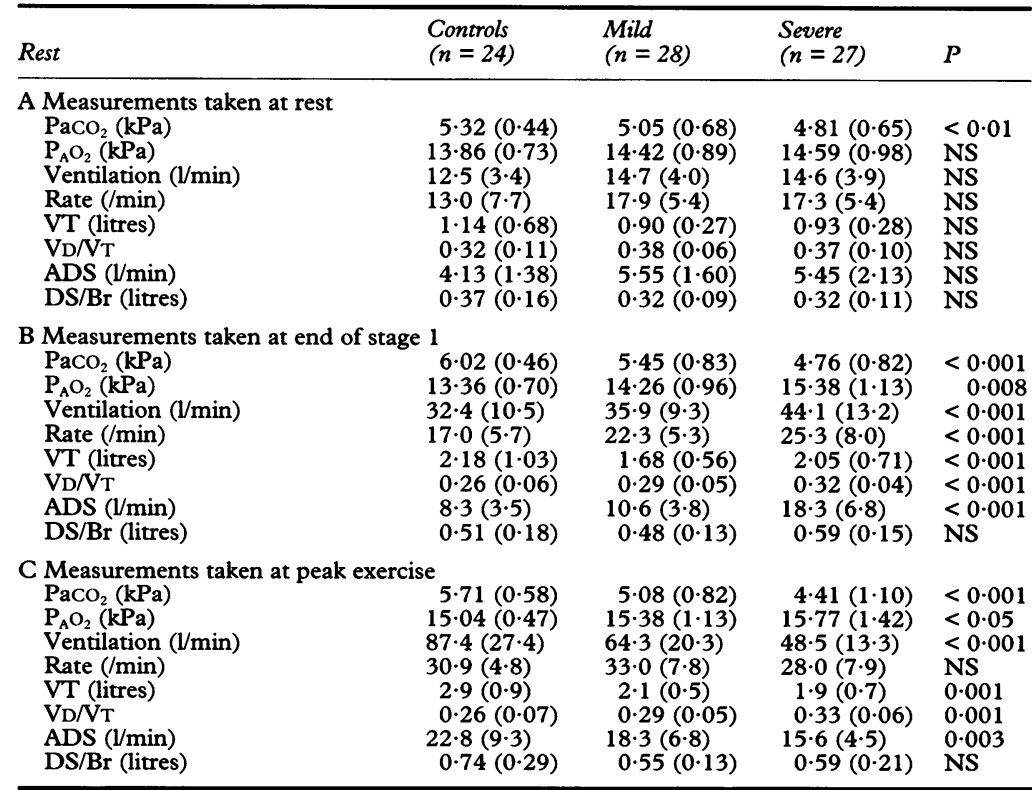

$\mathrm{PaCO}_{2}$ and $\mathrm{P}_{\mathrm{A}} \mathrm{O}_{2}$, partial pressures of arterial carbon dioxide and alveolar oxygen respectively Rate, respiratory rate; VT, tidal volume; $\mathrm{VD} / \mathrm{VT}$, dead space as a fraction of tidal volume; $\mathrm{ADS}$, absolute (minute) dead space ventilation; $\mathrm{DS} / \mathrm{Br}$, dead space volume per breath

$P$ values refer to the trend from controls to severe heart failure groups. for trend. At the end of further stages of exercise, ventilation was similar in all groups: stage 2: controls $44.5(15.6)$; mild heart failure ( $=21) 48 \cdot 3(13 \cdot 1)$; severe heart failure $(n=$ 5) 54.8 (11.9): $P=0.06$ for trend; stage 3 : controls $(n=21) 60 \cdot 4(16 \cdot 2)$; mild heart failure $(n=11) 59 \cdot 1(14 \cdot 6)$ : NS. This reflects the fact that the later stages of exercise consist of comparisons between controls and patients with mild heart failure, as the more severely affected patients had already stopped exercise. However, at peak exercise ventilation was significantly greater in the controls than in the patients: controls 87.4 (27.4); mild heart failure $64.3(20 \cdot 3)$, severe heart failure 48.5 (13.3): $P<0.001$ for trend. This suggests that ventilation itself was not a limiting feature and that ventilation reflected exercise load.

The respiratory pattern appeared to be altered in that patients had smaller tidal volumes and higher respiratory rates than controls at matched work loads (fig $4 \mathrm{~A}$ and $\mathrm{B}$ and table 5 A-C). However, at peak exercise, respiratory rate was similar in all groups, while tidal volume was significantly greater in the control group, at $2.9(0.9)$ v $2.0(0.6)$ litres: $\mathrm{P}<$ 0.001 . Dead space as a fraction of tidal volume $(\mathrm{VD} / \mathrm{VT})$ was greater in patients at stage 1 and at peak exercise (fig $5 \mathrm{~A}$ ), but minute dead space ventilation (litres $/ \mathrm{min}$ ) was greater in patients only at stage 1 (fig 5B). At peak exercise, minute dead space ventilation was greater in the control group, reflecting the greater peak expired ventilation. Dead space per breath was greater in controls at stage 3 and at peak exercise: stage 3: $0.65(0.20) \quad v 0.43$ $(0 \cdot 16)$ litres/breath: $P=0.004$; peak exercise: $0.74(0.29) v 0.57(0.17): \mathrm{P}=0.002$; fig $5 \mathrm{C}$. This presumably reflects the greater tidal volume in controls and hence higher absolute values for dead space per breath despite a higher dead space as a fraction of tidal volume in the patient group.

CORRELATES OF EXERCISE PERFORMANCE

As expected, in the patient group, there were strong correlations between peak $\dot{\mathrm{VO}}_{2}$ and exercise time $(r=0.87, \mathrm{P}<0.001), \dot{\mathrm{V}}_{2}(r$ $=0.79, \mathrm{P}<0.001)$, and ventilation at peak exercise $(r=0.57, \mathrm{P}<0.001)$. These correlations reflect the fact that as exercise duration increases, so inevitably do indices of ventilation and metabolic gas exchange. More interestingly, there was a good correlation between peak $\dot{\mathrm{VO}}_{2}$ and $\mathrm{PaCO}_{2}$ at peak exercise $(r=$ $0.58, \mathrm{P}<0.001$ ) (fig 6 ), suggesting that the inability to exercise in more severe heart failure is associated with hyperventilation relative to arterial carbon dioxide. There was no correlation with $\mathrm{FaO}_{2}$. Of the indices of dead space ventilation, there was a negative correlation between peak $\dot{\mathrm{Vo}}_{2}$ and peak VD/VT $(r=$ $-0.45, \mathrm{P}<0.001)$ but no correlations with either absolute dead space ventilation or dead space per breath (fig $7 \mathrm{~A}-\mathrm{C}$ ).

PREDICTORS OF EXERCISE PERFORMANCE

We wished to explore possible predictors of exercise capacity, that is, which resting variables, or variables from early in exercise, 

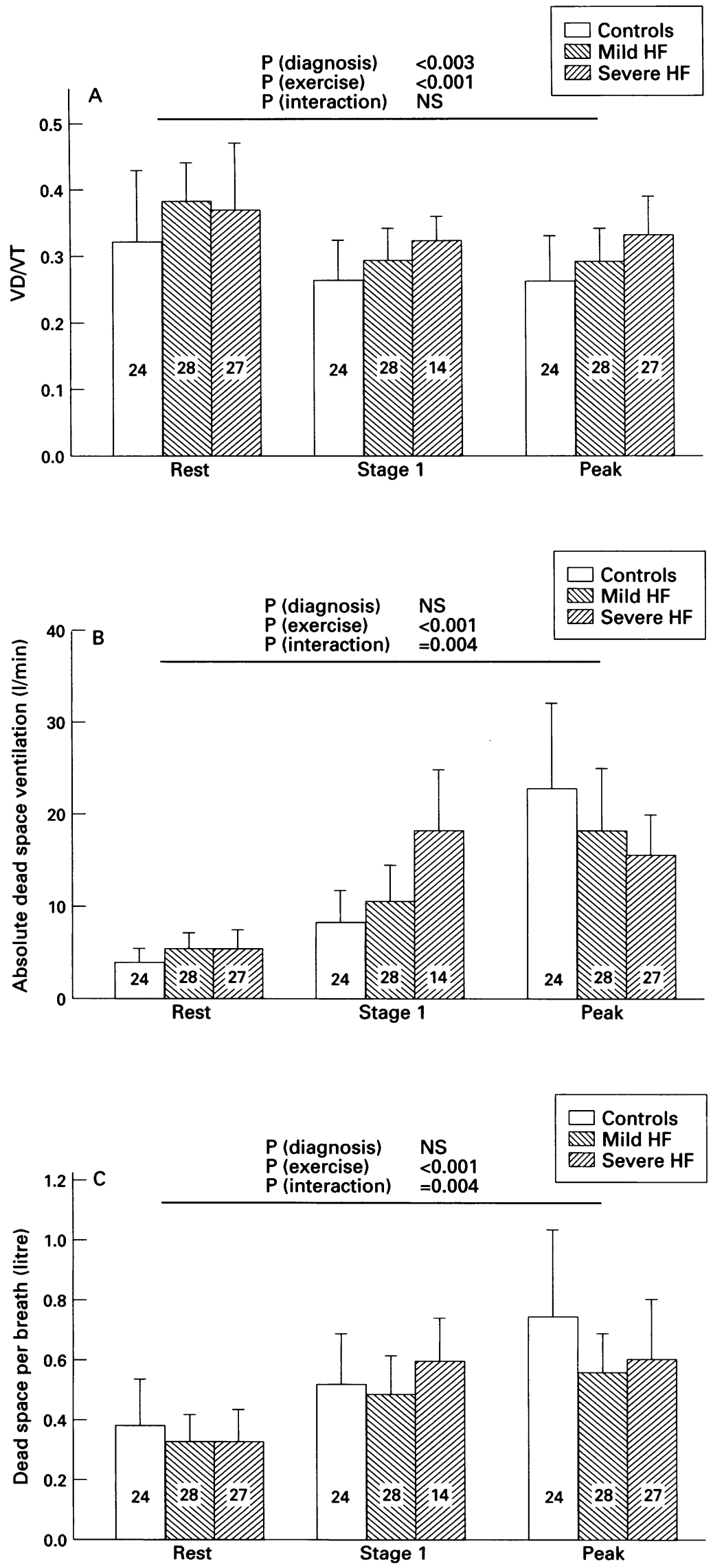

Figure 5 Ventilatory indices during exercise. $V D / V T$ is dead space as a fraction of tidal volume. Absolute dead space is minute dead space ventilation $(V D / V T \times V E)$ and dead space per breath is absolute dead space $\times$ respiratory rate. $P$ values as for fig 3.

would predict the eventual exercise capacity. In this group of patients there was a weak correlation between resting left ventricular ejection fraction and peak $\dot{\mathrm{VO}}_{2}(r=0.43, \mathrm{P}=$
0.009). $\mathrm{FEV}_{1}$ (as a percentage of the expected normal value to correct for body size) correlated with peak $\dot{\mathrm{V}}_{2}(r=0.52, \mathrm{P}=0.004)$, with peak VE $(r=0.60, \mathrm{P}<0.001)$, and with peak dead space per breath $(r=0.55, \mathrm{P}=$ $0.003)$. There was a weak negative correlation with peak $\mathrm{VD} / \mathrm{VT}(r=-0.49, \mathrm{P}=0.008)$ Similarly, percentage FVC correlated with peak $\dot{\mathrm{VO}}_{2}(r=0.52, \mathrm{P}=0.004)$, with ventilation at peak exercise $(r=0.73, \mathrm{P}<0.001)$, and with peak dead space per breath $(r=$ $0.62, \mathrm{P}<0.001)$. There was again a weak negative correlation with peak VD/VT $(r=$ $-0.47, P=0.01)$. There were no significant correlations between these spirometric variables and the $\dot{\mathrm{VE}} / \mathrm{V}_{\mathrm{CO}}$ slope. We used indices of ventilation at the end of stage 1 to attempt to predict eventual exercise performance. There was a correlation between peak $\dot{\mathrm{VO}}_{2}$ and the following stage 1 variables: $\dot{\mathrm{VE}}(r=$ $-0.47 ; \mathrm{P}<0.001), \mathrm{VD} / \mathrm{VT}(r=-0.38 ; \mathrm{P}=$ $0.005)$, and minute dead space ventilation $(r$ $=-0.56, \mathrm{P}<0.001)$. The potentially predictive variables were then entered into a stepwise multiple regression model. After the effects of the percentage $\mathrm{FEV}_{1}$ were accounted for $(r=$ $0.72, \mathrm{P}<0.001)$ only the $\dot{\mathrm{VE}} / \dot{\mathrm{V}} \mathrm{CO}_{2}$ slope was independently correlated with peak $\dot{\mathrm{V}} \mathrm{O}_{2}$, thereby increasing the overall correlation to $0 \cdot 85$, accounting for approximately $70 \%$ of the variation in peak $\mathrm{VO}_{2}$.

\section{Discussion}

Most previous experiments designed to assess the effects of chronic heart failure on ventilation during exercise, and the possibility of ventilatory abnormalities being determinants of exercise capacity in heart failure, have been conducted using cycle ergometry. ${ }^{7131617}$ Ventilation has been shown to be increased in heart failure. ${ }^{5-716}$ The ventilatory response relative to carbon dioxide production appears to be related to the severity of heart failure,$^{89}$ and it has been suggested by reference to the alveolar ventilation equation that the increase in ventilation is due to an increase in dead space ventilation..$^{7111}$ The ventilatory pattern in some experiments has been found to be abnormal in heart failure, with an increased respiratory rate at lower tidal volumes for a given minute ventilation, ${ }^{716}$ which may lead to an increase in the anatomical dead space ventilation.

Fewer experiments have been performed using treadmill exercise. Treadmill exercise is more often stopped by breathlessness than fatigue, ${ }^{1}$ and is a more reliable method for determining a plateau of oxygen consumption $\left(\dot{\mathrm{V}}_{2} \mathrm{max}\right) .{ }^{18}$ Even in fit subjects, bicycle exercise elicits a lower peak $\mathrm{VO}_{2}$ than treadmill exercise, ${ }^{119}$ as well as in heart failure, ${ }^{20}$ as a smaller muscle mass is used. Experiments using treadmill exercise have found that anatomical dead space is unlikely to be an important contributor to the increased ventilatory response, ${ }^{821}$ and other studies have drawn attention to the possible contribution of pulmonary abnormalities, in particular $\mathrm{FEV}_{1}$ and FVC. ${ }^{22}$ We undertook an investigation of venti- 
lation and metabolic gas exchange in a large group of heart failure patients during treadmill exercise in order to explore possible determinants of exercise tolerance in this setting.

\section{METABOLIC GAS EXCHANGE}

We have shown a reduced peak $\mathrm{Vo}_{2}$ in chronic heart failure, in common with other investigators, and a negative correlation between peak $\dot{\mathrm{V}} \mathrm{O}_{2}$ and the $\dot{\mathrm{V}} / \dot{\mathrm{V}} \mathrm{CO}_{2}$ slope. The level of venti-

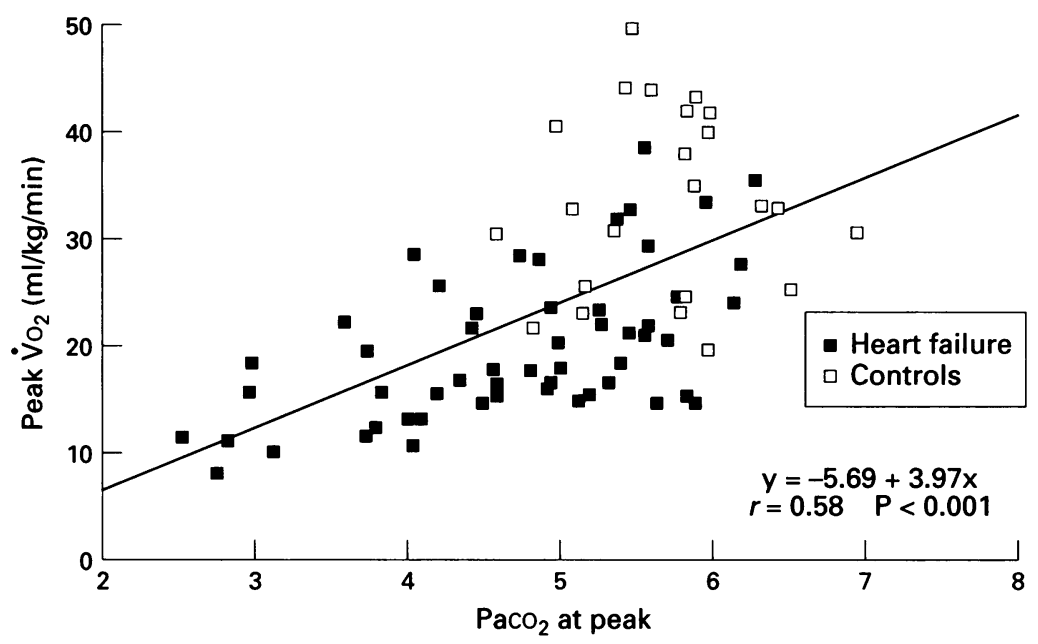

Figure 6 The relation between $\mathrm{PaCO}_{2}(\mathrm{kPa})$ at peak exercise and peak $\dot{\mathrm{O}}_{2}$. lation during the early stages of exercise is greater in the patient group, although during the later stages-after the more severely affected patients have "dropped out"-the levels of ventilation are similar in the two groups. The $\dot{V}_{2}$ at any stage during exercise is similar in both patients and controls, as the exercise load is the same. We have also found that during exercise, the arterial $\mathrm{CO}_{2}$ tension is lower in patients than in controls at any given stage, and that $\mathrm{CO}_{2}$ tension at peak exercise correlates with peak $\mathrm{VO}_{2}$. We have also shown that the alveolar oxygen tension is higher at each stage in the patients than controls.

\section{RESPIRATION}

As other investigators have shown that with bicycle exercise ${ }^{710}$ the respiratory pattern is altered in patients. At each stage, the respiratory rate is greater and the tidal volume smaller in patients with heart failure. At peak exercise, however, the respiratory rate is the same, with tidal volume greater in the control subjects, consistent with the greater total ventilatory response seen in this group (fig $4 \mathrm{~A}$ and B), albeit at a higher total workload.

Dead space was examined in three ways. Fractional dead space ventilation, as $\mathrm{VD} / \mathrm{VT}$ that is, dead space as a fraction of tidal volume-was greater in the patients during early
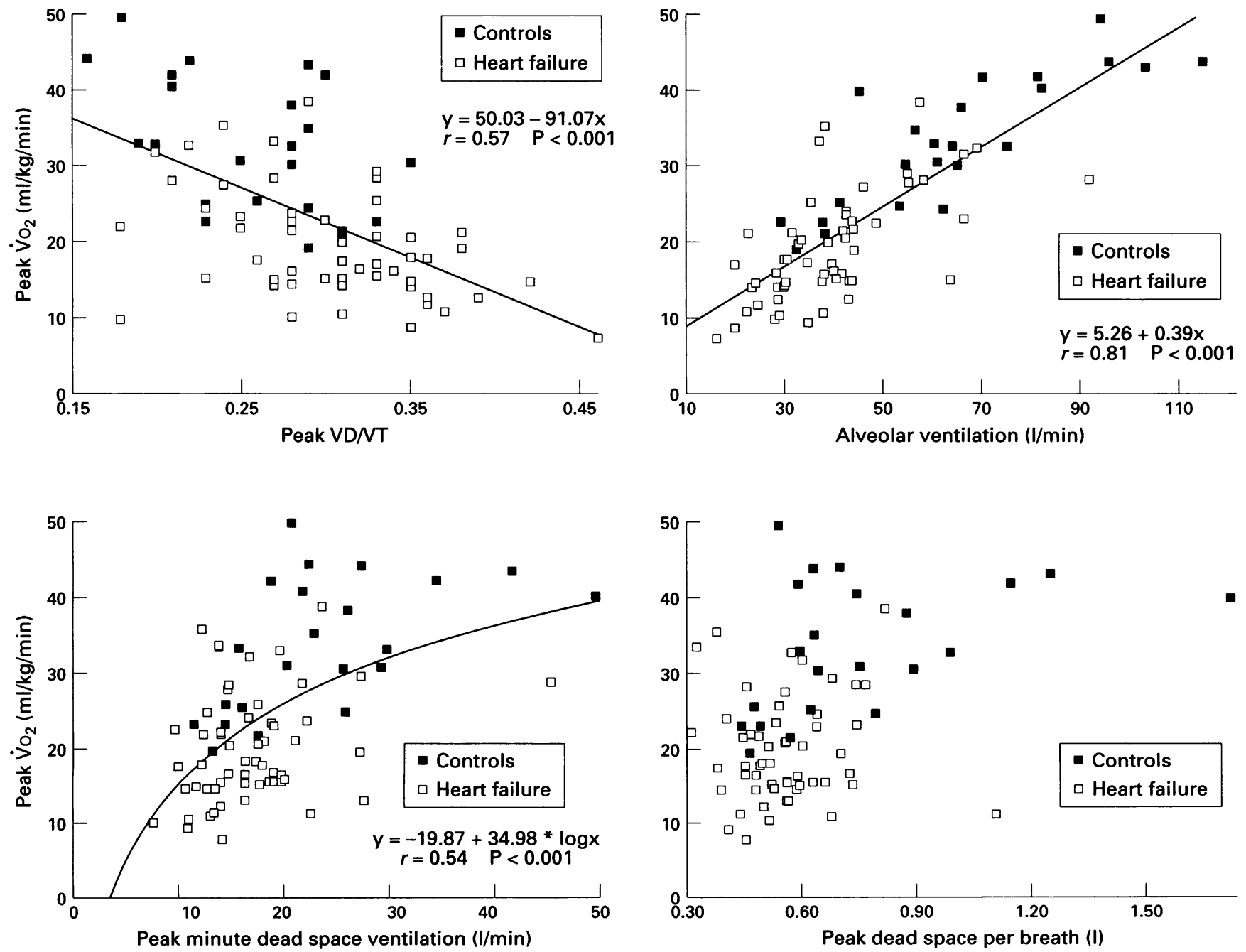

Figure 7 Possible correlates of peak $\mathrm{VO}_{2}$. 
stages, and at peak exercise. However, when dead space was interpreted as minute (or absolute) dead space ventilation-that is, total dead space ventilation per minute-it was higher in the patients early in exercise, but was greater in controls at peak exercise. This latter finding is consistent with the higher peak minute ventilation seen in the control group. We found dead space per breath to be the same in both groups early in exercise, but to be higher in the control group at peak exercise. This is a reflection of the fact that the increase in ventilation at peak exercise was proportionately greater in normal controls than the increase in dead space fraction in heart failure patients.

An increase in dead space per breath in patients relative to controls has previously been reported by Sullivan $e t a l,{ }^{7}$ and increased dead space has been widely accepted as a major contributing factor to the increased ventilatory response to exercise. However, this study rests on observations made in 18 patients and eight controls, using cycle exercise. The results from both the present study and Sullivan's ${ }^{7}$ are similar for the group with heart failure. However, in Sullivan's control group, $\mathrm{VD} / \mathrm{VT}$ fell at peak exercise to approximately $0 \cdot 15$. We estimate ${ }^{23}$ that the contribution of anatomical dead space alone in Sullivan's controls was in excess of $0 \cdot 1$, and it may be that the peak VD/VT was underestimated in Sullivan's control group. ${ }^{24}$

CONTROL OF VENTILATION

If a primary respiratory abnormality is responsible for the abnormal ventilatory response in heart failure, as has been suggested, ${ }^{71}{ }^{25}$ then there should be some signal generated by the respiratory abnormality resulting in an increased ventilatory drive. The signal would be expected to be an abnormality of arterial blood gas tensions. In this study, at equivalent stages, patients and controls have the same levels of metabolic gas exchange, yet ventilation is greater and arterial carbon dioxide tensions are lower in patients at each stage, suggesting that hyperventilation is occurring with respect to arterial gases. Similarly, alveolar oxygen tension is greater in patients than controls. Although alveolar oxygen is not the same as arterial oxygen tension, we and others have previously shown that the alveolar-arterial oxygen difference is unchanged in chronic heart failure,,$^{26}$ and in that case it seems likely that hyperventilation is taking place relative to arterial oxygen tension as well. In the current study, we have also seen that the lower the peak $\dot{\mathrm{VO}}_{2}$, the lower the arterial $\mathrm{CO}_{2}$ at peak exercise.

Previous investigators have also shown a small fall in arterial $\mathrm{CO}_{2}$ and a rise in arterial $\mathrm{O}_{2}$ during exercise. ${ }^{728} \mathrm{Herrlin}$ and Sylvén have shown an increase in arterial oxygen content ${ }^{29}$ - and Hachamovitch et al a decrease in arterial $\mathrm{CO}_{2}$ content ${ }^{30}$ - in heart failure consistent with our findings. This is the opposite of what would be expected if a respiratory abnormality were the cause of the increase in ventilation. The present findings suggest that the more limited patients are with heart fail- ure, the more they hyperventilate and reduce arterial $\mathrm{CO}_{2}$, and that the increased ventilatory response of heart failure probably has an alternative stimulus. Exercise is not, therefore, limited by an impairment in pulmonary function. ${ }^{26}$

It is difficult to envisage how an abnormality such as dead space per breath, or dead space fraction (VD/VT), could arise as a primary abnormality or indeed be sensed by the body. The observed abnormalities of ventilation-the increase in respiratory rate, lower tidal volumes, and lower ventilation at peak exercise - could be a response to an abnormal stimulus; the increase in dead space fraction could be a response to, rather than a cause of, excessive ventilation; a response seen as one which prevents arterial carbon dioxide tension from falling too low. Exercise is likely to be limited by something other than ventilatory abnormalities, as further suggested by the much lower peak ventilation seen in the patient group.

\section{EXERCISE LIMITATION}

Why then do patients with heart failure experience exercise limitation? In this experiment, we found correlations between $\mathrm{FEV}_{1}$ and FVC and peak $\mathrm{VO}_{2}$, as seen by others. ${ }^{22}$ This may suggest that airway flow is a limiting feature, but again, no change in blood gases is seen. Many of the variables are compound variables: $\mathrm{FEV}_{1}$, for example, is a reflection not only of airway function but of respiratory muscle strength. Much recent work has drawn attention to the abnormalities of skeletal ${ }^{3132}$ and respiratory muscle ${ }^{334}$ in heart failure. The possibility exists that there is an underlying abnormality of skeletal muscle resulting in both the sensation of muscle fatigue and an excessive ventilatory stimulus. ${ }^{35}{ }^{36}$ The ventilatory abnormalities in chronic heart failure could, therefore, be secondary to changes elsewhere in the body, and in particular in skeletal muscle.

\section{LIMITATIONS TO THE PRESENT STUDY}

We only measured arterial blood gas tensions in a minority of our patients, and used the end tidal $\mathrm{CO}_{2}$ as an estimate of arterial $\mathrm{CO}_{2}$. While this appears justified on the basis of blood gas analysis in a subset of our patients, this may not have been representative of the group as a whole. Indeed, it might be expected that as VD/VT becomes greater any difference between arterial and end tidal $\mathrm{CO}_{2}$ would increase, ${ }^{37}$ although the difference was small in a group of anaesthetised subjects. $^{38}$

We cannot completely exclude a role for an increase in dead space ventilation during exercise in chronic heart failure. However, if this were a major pathophysiological mechanism, it would require a greatly increased ventilatory response to a change in arterial $\mathrm{CO}_{2}$ too small to detected.

ALC was supported by the Robert Luff Foundation. JWS was the Viscount Royston Trust and the British Heart Foundation. 
1 Fink LI, Wilson JR, Ferraro N. Exercise ventilation and pulmonary artery wedge pressure in chronic stable congestive heart failure. Am $\mathcal{f}$ Cardiol 1986;57:249-53.

2 Lipkin DP, Canepa-Anson R, Stephens MR, Poole-Wilson PA. Factors determining symptoms in heart failure: comparison of fast and slow exercise tests. Br Heart $\mathcal{f} 1986$; 55:439-45

3 Weber KT, Wilson JR, Janicki J, Likoff MJ. Exercise testing in the evaluation of the patient with chronic cardi

ure. Am Rev Respir Dis 1984;129(Suppl):S60-2. Franciosa JA, Park M, Levine TB. Lack of correlation between exercise capacity and indexes of resting left ven-
tricular performance in heart failure. Am $\mathcal{F}$ Cardiol 1981; tricular pert.

5 Higginbotham MB, Morris KG, Conn EH, Coleman RE Cobb FR. Determinants of variable exercise performance among patients with severe left

6 Rubin SA, Brown HV. Ventilation and gas exchange during exercise in severe chronic heart failure. Am Rev Respir Dis 1984;129(suppl):S63-64.

7 Sullivan MJ, Higginbotham MB, Cobb FR. Increased exercise ventilation in patients with chronic heart failure: intact ventilatory control despite haemodynamic and pulmonary abnormalities. Circulation 1988;77:552-9.

8 Buller NP, Poole-Wilson PA. Mechanism of the increased ventilatory response to exercise in patients with chronic heart failure. Br Heart $₹$ 1990;63:281-3.

9 Davies SW, Emery TM, Watling MII, Wannamethee G Lipkin DP. A critical threshold of exercise capacity in the ventilatory response to exercise in heart failure. Br Heart $f$ ventilatory response

10 Myers J, Salleh A, Buchanan N, Smith D, Neutel J, Bowes $\mathrm{E}$, et al. Ventilatory mechanisms of exercise intolerance in $\mathrm{E}$, et al. Ventilatory mechanisms of exercise intoler

11 Metra M, Dei Cas L, Panina G, Visioli O. Exercise hyperventilation chronic congestive heart failure and its relation to functional capacity and hemodynamics. $\mathrm{Am} \mathcal{F}$ Cardiol 1992;70:622-8.

12 Rubin SA, Brown HV, Swan HJC. Arterial oxygenation and arterial oxygen transport in chronic myocardial failure at rest, during exercise and after hydralazine treatment. Circulation 1982;66:143-8.

13 Franciosa JA, Leddy CL, Wilen M, Schwartz DE. Relation between haemodynamic and ventilatory responses in determining exercise capacity in severe congestive heart failure. Am $\mathcal{F}$ Cardiol 1984;53:127-34.

14 Davies N, Denison DM. Measurement of metabolic gas exchange and minute volume by mass spectrometry exchange and minute volume by
alone. Resp Physiol 1979;36:261-7.

15 Clark AL Volterrani M, Piepoli $M$, Coats AJS Factors which alter the relationship between ventilation and carbon dioxide production during exercise: implications for the understanding of the increased ventilatory response to exercise in chronic heart failure. Eur $\mathcal{f}$ Appl Physio 1996;73:144-8.

16 Weber KT, Kinasewitz GT, Janicki JS, Fishman AP Oxygen utilisation and ventilation during exercise in patients with chronic cardiac failure. Circulation 1982;65 1213-23.

17 Szlachcic J, Massie BM, Kramer BL, Topic N, Tubau J. Correlates and prognostic implication of exercise capac55:1037-42.

18 Wilson JR, Fink LI, Ferraro N, Dunkman WB, Jones RA. The use of maximal bicycle exercise testing with respiratory gas analysis to assess exercise performance in patients with congestive heart failure secondary to nary artery disease or to idiopathic dilated cardiomyo- pathy. Am f Cardiol 1986;58:601-6.

19 Poole-Wilson PA. Exercise as a means of assessing heart failure and its response to treatment. Cardiology 1989;76: 347-56

20 Riley M, Northridge DB, Henderson E, Stanford CF, Nicholls DP, Dargie HJ. The use of an exponential protocol for bicycle and treadmill exercise testing in patients
with chronic cardiac failure. Eur Heart f 1992;13:1363-7.

21 Clark AL, Coats AJS. Effects of induced changes in anatomical dead space ventilation on the relationship between ventilation and carbon dioxide production in normal man. Eur f Clin Invest 1993;23:428-32.

22 Kraemer MD, Kubo SH, Rector TS, Brunsvold N, Bank AJ. Pulmonary and peripheral vascular factors are imporAJ. Pulmonary and peripheral vascular factors are important determinants of peak exercise oxygen uptake in
patients with heart failure. $\mathcal{F} \mathrm{Am}$ Coll Cardiol 1993;21: patients

23 Cotes JE. Lung function, 4th ed. Oxford: Blackwell Scientific Publications 1979:244.

24 Wasserman K, Whipp BJ, Casaburi R. Respiratory control during exercise. In: Cherniak NS, Widdicombe JG, eds. Handbook of physiology, section 3, vol II: 595-619.

25 Wada O, Asanoi H, Miyagi K, Ishizaka S, Kameyama T, Seto $\mathrm{H}$, et al. Importance of abnormal lung perfusion in excessive exercise ventilation in chronic heart failure. $\mathrm{Am}$ Heart $\mathcal{~ 1 9 9 3 ; 1 2 5 : 7 9 0 - 8 . ~}$

26 Clark AL, Volterrani M, Cerquetani E, Ludman PF, Swan JW, Poole-Wilson PA, et al. Ventilation-perfusion matching in chronic heart failure. Int $\mathcal{F}$ Cardiol 1995;48:259-70.

27 Rajfer SA, Nemanich JW, Shurman AJ, Rossen JD. Metabolic responses to exercise in patients with heart Metabolic responses to exercise in patients
failure. Circulation 1987;76(suppl VI):VI46-53.

28 Rubin SA, Brown HV. Ventilation and gas exchange during exercise in severe chronic heart failure. Am Rev Respir Dis 1984;129(suppl):S63-4.

29 Herrlin B, Sylvén C. Increased arterial oxygen content-an important compensatory mechanism in chronic moderate heart failure. Cardiovasc Res 1991;25:384-90.

30 Hachamovitch R, Brown HV, Rubin SA. Respiratory and circulatory analysis of $\mathrm{CO}_{2}$ output during exercise in chronic heart failure. Circulation 1991;84:605-12.

31 Massie BM, Conway M, Yonge R, Frostick S, Ledingham J, Sleight $\mathrm{P}$, et al. Skeletal muscle metabolism in patients with congestive heart failure: relation to clinical severity and blood flow. Circulation 1987;76:1009-19.

32 Mancini DM, Walter G, Reichnek N, Lenkinski $R$, McCully KK, Mullen $\mathrm{J}$, et al. Contribution of skeletal muscle atrophy to exercise intolerance and altered muscle metabolism in heart failure. Circulation 1992;85: 1364-73.

33 Mancini DM, Henson D, LaManca J, Levine S Respiratory muscle function and dyspnea in patients with Respiratory muscle function and dyspnea in patients with
chronic congestive heart failure. Circulation 1992;86: 909-19.

34 Hammond MD, Bauer KA, Sharp JT, Rocha RD Respiratory muscle strength in congestive heart failure. Chest 1990;98:1091-4.

35 Volterrani M, Clark AL, Ludman PF, Swan JW, Adamopoulos S, Piepoli M, et al. Determinants of exercise capacity in chronic heart failure. Eur Heart $\mathcal{F} 1994$; 15:801-9.

36 Coats AJS, Clark AL, Piepoli M, Volterrani M, PooleWilson PA. Symptoms and quality of life in heart failure: the muscle hypothesis. Br Heart $\mathcal{F}$ 1994;72 (suppl):36-9.

37 Nunn JF. Applied respiratory physiology, 3rd ed. London: Butterworth, 1987

38 Nunn JF, Hill DW. Respiratory dead space and arterial to endtidal $\mathrm{CO}_{2}$ difference in anaesthetised man. $\mathcal{F} \mathrm{Appl}$ Physiol 1960;15:383-9. 